\title{
Augmentation of light therapy in difficult-to-treat depressed patients: an open-label trial in both unipolar and bipolar patients
}

This article was published in the following Dove Press journal:

Neuropsychiatric Disease and Treatment

9 September 2015

Number of times this article has been viewed

\author{
Giovanni Camardese \\ Beniamino Leone' \\ Riccardo Serrani ${ }^{\prime}$ \\ Coco Walstra' \\ Marco Di Nicola' \\ Giacomo Della Marca ${ }^{2}$ \\ Pietro Bria' \\ Luigi Janiri' \\ 'Institute of Psychiatry and \\ Psychology, ${ }^{2}$ Institute of Neurology, \\ Catholic University of the Sacred \\ Heart, Rome, Italy
}

Objectives: We investigated the clinical benefits of bright light therapy (BLT) as an adjunct treatment to ongoing psychopharmacotherapy, both in unipolar and bipolar difficult-to-treat depressed (DTD) outpatients.

Methods: In an open-label study, 31 depressed outpatients (16 unipolar and 15 bipolar) were included to undergo 3 weeks of BLT. Twenty-five completed the treatment and 5-week follow-up.

Main outcome measures: Clinical outcomes were evaluated by the Hamilton Depression Rating Scale (HDRS). The Snaith-Hamilton Pleasure Scale and the Depression Retardation Rating Scale were used to assess changes in anhedonia and psychomotor retardation, respectively.

Results: The adjunctive BLT seemed to influence the course of the depressive episode, and a statistically significant reduction in HDRS scores was reported since the first week of therapy. The treatment was well-tolerated, and no patients presented clinical signs of (hypo)manic switch during the overall treatment period. At the end of the study (after 5 weeks from BLT discontinuation), nine patients (36\%, eight unipolar and one bipolar) still showed a treatment response. BLT augmentation also led to a significant improvement of psychomotor retardation.

Conclusion: BLT combined with the ongoing pharmacological treatment offers a simple approach, and it might be effective in rapidly ameliorating depressive core symptoms of vulnerable DTD outpatients. These preliminary results need to be confirmed in placebo-controlled, randomized, double-blind clinical trial on larger samples.

Keywords: light therapy, unipolar depression, bipolar depression, anhedonia, psychomotor dysfunction

\section{Introduction}

Major depression is a highly prevalent condition as well as a debilitating psychiatric illness that has a negative impact on individual and community health. ${ }^{1}$ Antidepressant drugs are the mainstay of the treatment of depression; however, their efficacy is still lower than desired, and many patients present subsyndromal residual symptoms after the initial clinical response. Up to $15 \%$ of cases will remain significantly depressed even after multiple pharmacological approaches, ${ }^{2}$ with a negative impact on clinical course. $^{3}$

Since a partial response to treatment represents a widespread condition among depressed patients and should be readily identified to decide the most appropriate treatment plan, many helpful systems for staging levels of treatment resistance have been proposed for major depression. ${ }^{4}$ In this way, Rush et al described "difficult-to-treat depression"as a clinical condition which includes both those patients who do not respond 
adequately to one or more established treatments and those in whom a successful treatment is prevented by concomitant conditions, precluding the optimal delivery of potentially effective treatments. Such circumstances mainly involve limited adherence to treatment, adverse side effects preventing an adequate dose or duration of treatment, and comorbid axis I, II, or III conditions. ${ }^{5}$ Hence, difficult-to-treat depressed (DTD) patients form a clinical population of vulnerable subjects, representing a common medical challenge for clinicians who often have to develop individualized therapeutic decisions based on limited scientific evidence. Many augmentation strategies have been developed to increase the efficacy of antidepressant treatments, and alternative strategies based on multidisciplinary competences are probably essential.

Among safe and less-demanding treatment strategies, a growing number of evidence supports the usefulness of chronotherapeutic interventions, such as bright light therapy (BLT), in the management of patients suffering from mood disorders.

When combined with antidepressants, BLT hastens recovery with improvements since the first week of treatment. ${ }^{6,7}$ Clinical benefits are well known for unipolar depressed patients, but despite the amount of data provided by Benedetti ${ }^{8}$ on combined chronotherapeutic intervention, only few trials have looked at BLT alone as an augmentation of pharmacotherapy for bipolar depression. ${ }^{9,10}$

Because of brief latency of action, BLT alone ${ }^{11,12}$ has been little studied in the vulnerable clinical population of DTD patients. Hence, the main aim of our study was to explore the effects of BLT augmentation on clinical outcome of these patients, and compare unipolar and bipolar subjects. We tested BLT combined with ongoing medication as a first-line choice for both more vulnerable patients (with concomitant medical and/or psychiatric comorbidity that preclude the optimal delivery of the ongoing treatment) and patients with stage I treatment-resistant depression (TRD) (those who failed to achieve a remission after the first pharmacological trial at an adequate dose). Finally, we observed the effectiveness of such an approach both in the acute phase and after BLT discontinuation over 8 weeks.

\section{Methods}

Thirty-one depressed outpatients (16 unipolar and 15 bipolar without seasonal pattern) were enrolled in the study. A total of 110 outpatients referred for the treatment of depressive episode at the Institute of Psychiatry of the "Agostino Gemelli" University Polyclinic in Rome were screened. Of these, 79 did not fulfill our inclusion criteria. The population consisted of 18 women and 15 men with a mean age of 47.6 years. Subjects were included if they 1) met diagnostic criteria for a major depressive episode according to Diagnostic and Statistical Manual of Mental Disorders, Fourth Edition, Text Revision (DSM-IV-TR), 2) had a baseline 21-item Hamilton Depression Rating Scale (HDRS-21) score of 15 or higher, ${ }^{13}$ and 3 ) had a condition of difficult-totreat depression that, as determined by Rush et al, ${ }^{5}$ included both patients partially responding to at least a 5-week openlabel trial of an adequate dose of antidepressant monotherapy and those in whom a successful treatment is prevented by concomitant medical or psychiatric conditions.

Subjects who did not respond to two or more different classes of adequate antidepressant trials according to the classical definition of stage II TRD were excluded. Other exclusion criteria were 1) a diagnosis of non-affective psychotic disorder, 2) a diagnosis of substance use disorders within the last year, 3) a diagnosis of dementia or other cognitive disorders, 4) electroconvulsive therapy (ECT) within 1 year prior to enrollment, 5) recent history of suicide attempts, and 6) ocular disease (glaucoma, cataracts, retinal detachment, retinopathy). Subjects having general medical conditions or personality disorders affecting treatment adherence or tolerability were not excluded. The local ethics committee approved the study, and a written informed consent was obtained from all subjects.

The psychopathological status was assessed by the same experienced rater blind to the week of study and the study design. At baseline, severity of mood disorder was evaluated with HDRS-21 and Mania Rating Scale (MRS); ${ }^{14}$ in order to identify a specific antidepressant effect on depression core items, a secondary outcome measure, the six-item Hamilton Depression Rating Scale (HDRS-6), was used. ${ }^{15}$ The SnaithHamilton Pleasure Scale (SHAPS) ${ }^{16}$ was used to assess anhedonia, whereas the Depression Retardation Rating Scale (DRRS) ${ }^{17}$ was used for psychomotor retardation.

In order to evaluate treatment outcomes, HDRS-21, HDRS-6, and MRS were repeated at week 1, week 3, week 4, and week 8 after onset of BLT. SHAPS and DRRS were repeated after 8 weeks.

Responders were defined by a decrease of at least $50 \%$ in the HDRS-21 total score from baseline. The season during which BLT took place was registered. Autumn/winter and spring/summer were taken together as the two seasons with a shorter and longer photoperiod, respectively.

\section{Study intervention}

BLT was added to the ongoing medication treatment after recruitment, and nothing was altered in psychopharmacotherapy 
during the experiment. At baseline, all subjects were required to be on a stable dose of their psychotropic medication for at least 4 weeks prior to enrollment. Unipolar patients were taking antidepressant drugs (ademetionine, escitalopram, duloxetine, agomelatine, clomipramine, fluoxetine, citalopram, sertraline, amisulpride, nortriptyline, amitriptyline, and trazodone). Bipolar patients were required to take at least one mood stabilizer, with the exception of a patient who was pregnant (lithium carbonate, lamotrigine, and valproic acid). Patients on lithium or valproic acid had plasma levels higher than $0.4 \mathrm{mEq} / \mathrm{L}$ and $50 \mathrm{mg} / \mathrm{mL}$, respectively. Six bipolar patients were taking antidepressants (duloxetine, agomelatine, nortriptyline, sertraline, venlafaxine, clomipramine).

Once enrolled, no change in the dosage of any psychotropic medication was allowed, and any photosensitizing medication was prohibited. Ten patients took benzodiazepines (up to $2 \mathrm{mg}$ of lorazepam-equivalents per day) or sleeping drugs (zolpidem 5-10 mg or zaleplon 5-10 mg) for insomnia.

Patients were instructed to undergo daily treatment in their own homes between 5.45 am and 8.15 am, for 3 weeks, and the regimen was carefully explained to each subject. The exact time schedule for light therapy sessions was defined following a predictive algorithm based on Morningness-Eveningness Questionnaire scores. ${ }^{18-22}$ According to most studies, we chose an exposure of 30 minutes at approximately 10,000 lx for 3 weeks. After the first week of treatment, partial or no responders were instructed to increase the exposure to 45 minutes/day for the next 2 weeks. ${ }^{23,24}$

\section{Light boxes}

Light therapy was administered by means of the Daylight Simulator "Day-Light" Classic Model (Uplift Technologies Inc, Nova Scotia, Canada). This device measures $31.8 \mathrm{~cm} \times$ $40.6 \mathrm{~cm} \times 7.6 \mathrm{~cm}$, with a lens material of high-impact polycarbonate, $99.3 \% \mathrm{UV}$ filter, and three $36 \mathrm{~W}$ fluorescent light tubes of 4,000 K color temperature, with height-adjustable legs and two light intensity settings of 10,000 lx and 7,000 lx at 12 in $(30.5 \mathrm{~cm})$. Subjects were instructed to place the box on a desk or tabletop at an angle of $15^{\circ}$, adjust the height so that the center of the box would be at eye level, and use the 10,000 lx.

\section{Data analysis}

Basic descriptive statistics were calculated for demographic and clinical variables. We performed a Shapiro-Wilk test in order to examine variables distribution. Descriptive analyses were carried out using Student's $t$-test, $\chi^{2}$ test, and the oneway or repeated-measures analysis of variance (ANOVA). Assessment scale scores before and after treatment were compared using paired samples $t$-test or Wilcoxon signedranks test. The trends in the mean scores in individual assessment scales and the influence of factor affecting course of symptoms were determined using repeated measures ANOVA with multiple comparison correction (Bonferroni adjustment). All efficacy analyses used the last-observationcarried-forward approach. Comparisons of response rates between unipolar and bipolar patients and between seasons of treatment have been estimated using a $2 \times 2$ crosstab and $\chi^{2}$ test. All tests were two-tailed, and significance was set with an alpha value of 0.05 . Data were analyzed using SPSS 15.0 (SPSS 15.0, Chicago, IL, USA).

\section{Results}

Thirty-one outpatients underwent baseline observation and were assigned to BLT augmentation. Two unipolar and four bipolar subjects dropped out (19\% of total sample): one (unipolar) patient had an incoming adverse event not related to treatment (patient decided to stop BLT after starting an antibiotic therapy for a toothache) and five (one unipolar and four bipolar) patients did not comply with the treatment procedures (not properly respecting wake-up time or instructions on light exposure). Bipolarity did not significantly affect the dropout rate $\left(\chi^{2}=0.995 ; P=0.318\right)$. Twenty-five patients (14 unipolar and eleven bipolar) completed the 3 weeks of treatment (Figure 1). All demographic and clinical characteristics are summarized in Table 1. At baseline, patients showed a moderate burden of depressive

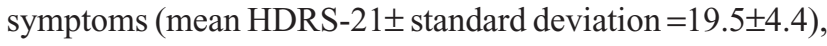
relevant psychomotor retardation (score $>10$ on the DRRS), and/or anhedonic features. No significant differences were observed at basal evaluation between unipolar and bipolar patients (Table 2).

Depressive symptoms improved significantly during adjunctive BLT in the overall study sample. A repeatedmeasures ANOVA determined that mean HDRS-21 total scores significantly differed between time points $(F[4,80]=16.306 ; P<0.001)$ (Figure 2). A Bonferroni correction showed a statistically significant reduction in HDRS-21 scores since the first week of therapy $(P=0.001)$. A statistically significant effect of time was observed since the first week on the HDRS-6 scores, as well $(F[4,80]=14.875 ; P<0.001$; Bonferroni correction, $P=0.009$ ) (Figure 2). Twenty-three patients received extra daily exposure of light (shifting from 30 minutes to 45 minutes) after first week of treatment, but this did not have an independent effect over the course of depressive symptoms $(F[2.719,62.538]=0.964 ; P=0.409)$. During the overall treatment period, no significant changes 


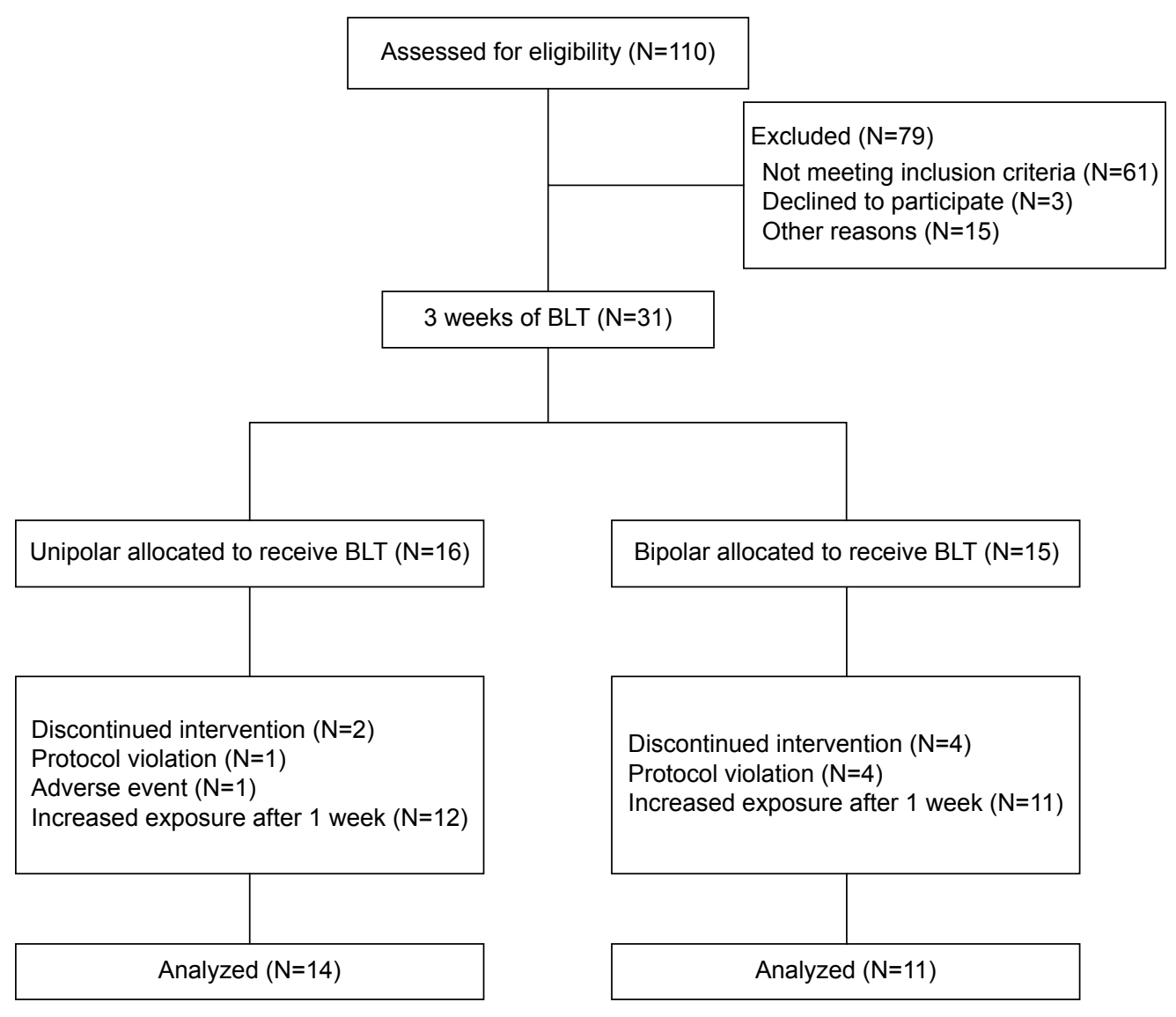

Figure I Flowchart of study design.

Abbreviation: BLT, bright light therapy.

were reported in MRS scores, and no patient presented clinical signs of a (hypo)manic switch. A repeated-measures ANOVA determined that mean MRS total scores did not significantly change between time points $(F[2.804,56.087]=2.025$; $P=0.125)$. Although MRS scores increased in bipolar group, no statistically significant difference was found between time points (Wilcoxon signed-ranks test: $Z=-0.4921 ; P=0.623$ ). After 1 week from BLT discontinuation (at week 4 of the study), seven patients (28\%) showed a treatment response. After another month (at week 8 of the study), they were still responders, and two more patients achieved this treatment outcome (in total nine patients; $36 \%$ ).

Table I Demographic and clinical features at baseline

\begin{tabular}{|c|c|c|c|c|c|c|}
\hline \multicolumn{3}{|l|}{ Diagnosis } & \multicolumn{2}{|l|}{ Count } & \multicolumn{2}{|l|}{ Percent } \\
\hline MDD & & & 14 & & 56 & \\
\hline BD-I & & & 4 & & 16 & \\
\hline BD-2 & & & 7 & & 28 & \\
\hline \multirow{2}{*}{$\begin{array}{l}\text { Other demographic } \\
\text { features }\end{array}$} & \multicolumn{2}{|c|}{ Overall } & \multicolumn{2}{|c|}{ Unipolar } & \multicolumn{2}{|l|}{ Bipolar } \\
\hline & Mean & SD & Mean & SD & Mean & SD \\
\hline Age (years) & 47.6 & 13.5 & 46.8 & 12.2 & 48.6 & 13.9 \\
\hline Age at onset (years) & 33.7 & 10.2 & 33.9 & 10.2 & 33.5 & 9.8 \\
\hline Duration of illness (years) & 13.9 & 11.9 & 12.9 & 11.9 & 15.1 & 14.1 \\
\hline Previous episodes & 5.2 & 3.6 & 2.9 & 1.5 & 7.5 & 4.0 \\
\hline Duration of current episode (months) & 7.8 & 9.6 & 11.1 & 10.6 & 4.5 & 6.4 \\
\hline Season of treatment & Count & Percent & Count & Percent & Count & Percent \\
\hline Autumn/winter & 12 & 48 & 5 & 36 & 7 & 64 \\
\hline Spring/summer & 13 & 52 & 9 & 64 & 4 & 36 \\
\hline
\end{tabular}

Abbreviations: MDD, major depressive disorder; BD-I, bipolar disorder type I; BD-2, bipolar disorder type 2; SD, standard deviation. 
Table 2 Psychometric features from all assessments, both for unipolar and bipolar patients

\begin{tabular}{|c|c|c|c|c|c|c|}
\hline \multirow[t]{2}{*}{ Scale } & \multicolumn{2}{|c|}{ Overall } & \multicolumn{2}{|c|}{ Unipolar } & \multicolumn{2}{|c|}{ Bipolar } \\
\hline & Mean & SD & Mean & SD & Mean & SD \\
\hline HDRS-2 $\mathrm{I}_{\text {baseline }}$ & 19.5 & 4.4 & 18.4 & 4.2 & 20.9 & 4.4 \\
\hline HDRS- $2 I_{\text {week I }}^{\text {basiline }}$ & 15.3 & 5.3 & 13.9 & 5.7 & 17.2 & 4.3 \\
\hline HDRS-2I week 3 & 13.8 & 5.5 & 11.9 & 3.8 & 16.3 & 6.5 \\
\hline HDRS-2I I week 4 & 13.8 & 6.1 & 11.6 & 5.2 & 16.5 & 6.3 \\
\hline HDRS-2I $I_{\text {week } 8}$ & 12.2 & 6.9 & 9.6 & 6.4 & 15.4 & 6.4 \\
\hline HDRS-6 $6_{\text {baseline }}$ & 9.4 & 2.7 & 9.0 & 2.6 & 9.9 & 2.9 \\
\hline HDRS-6 ${ }_{\text {week } 1}$ & 7.4 & 3.4 & 6.6 & 3.3 & 8.4 & 3.3 \\
\hline HDRS-6 6 week 3 & 6.8 & 3.0 & 5.6 & 1.6 & 8.2 & 3.8 \\
\hline HDRS-6 6 week 4 & 6.8 & 3.8 & 5.4 & 3.0 & 8.5 & 4.3 \\
\hline HDRS-6 6 week 8 & 5.7 & 4.1 & 3.9 & 2.8 & 8.0 & 4.3 \\
\hline $\mathrm{MRS}_{\text {baseline }}$ & 3.0 & 2.4 & 3.2 & 2.5 & 2.7 & 2.3 \\
\hline$M R S_{\text {week I }}$ & 2.4 & 1.7 & 2.6 & 1.7 & 2.1 & 1.7 \\
\hline $\mathrm{MRS}_{\text {week } 3}$ & 2.0 & 1.7 & 1.5 & 1.6 & 2.8 & 1.7 \\
\hline $\mathrm{MRS}_{\text {week } 4}$ & 3.4 & 2.8 & 2.4 & 2.2 & 4.5 & 3.1 \\
\hline$M R S_{\text {week } 8}$ & 2.7 & 2.3 & 2.3 & 2.3 & 3.3 & 2.2 \\
\hline DRRS $_{\text {baseline }}$ & 14.5 & 9.3 & 13.9 & 9.8 & 15.4 & 9.0 \\
\hline $\mathrm{DRRS}_{\text {week } 8}$ & 8.1 & 6.8 & 6.3 & 5.2 & 10.6 & 8.3 \\
\hline SHAPS $_{\text {baseline }}$ & 2.6 & 3.6 & 2.9 & 3.4 & 2.3 & 3.9 \\
\hline SHAPS $_{\text {week } 8}$ & 2.8 & 4.5 & 2.8 & 4.5 & 2.9 & 4.8 \\
\hline
\end{tabular}

Abbreviations: SD, standard deviation; HDRS-2I, Hamilton Depression Rating Scale (2I items); HDRS-6, Hamilton Depression Rating Scale (6 items); MRS, Mania Rating Scale; DRRS, Depressive Retardation Rating Scale; SHAPS, Snaith-Hamilton Pleasure Scale.

As reported by HDRS-21 scores, we observed a substantial clinical improvement, in both unipolar and bipolar groups (Figure 3). Although bipolar patients showed a more severe psychopathological burden throughout the treatment period, bipolarity did not seem to have an independent effect over the course of depressive symptoms $(F[4,76]=14.850$; $P=0.826)$. However, when considering differences between mean HDRS-21 scores, unipolar patients showed a significantly better outcome as from week 3 until the end of the study (Figure 3). At the end of the study, unipolar patients

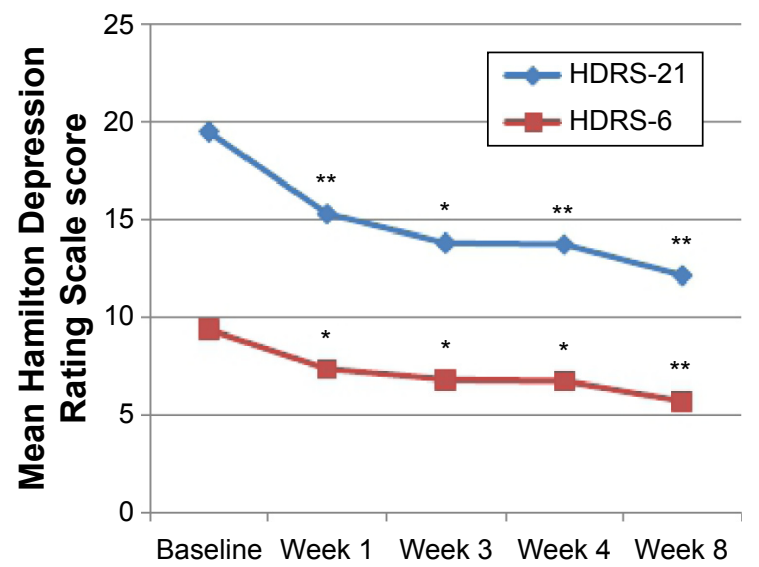

Figure 2 Mean overall HDRS-2I and HDRS-6 scores.

Notes: Repeated measures showed that mean HDRS scores significantly decreased since the first week of treatment. In comparison with baseline, a significant reduction was observed at week I, week 3, week 4, and week 8 . $* P<0.05$. $* * P<0.00 \mathrm{I}$. Abbreviations: HDRS-2I, Hamilton Depression Rating Scale (2I items); HDRS-6, Hamilton Depression Rating Scale (6 items). also showed a significantly better response rate than bipolar patients ( 8 and 1 , respectively; $\chi^{2}=6.173 ; P=0.013$ ).

In order to determine the role of other demographic, clinical, and treatment variables in the course of depressive symptoms, we performed a series of repeated-measures ANOVAs. No main effect or interactions between factors were statistically significant. Concerning season of treatment, at the end of follow-up, patients in the spring/summer season had a significantly higher remission rate (HDRS score $<8$; $\left.\chi^{2}=4.427 ; P=0.035\right)$. We checked for confounding between

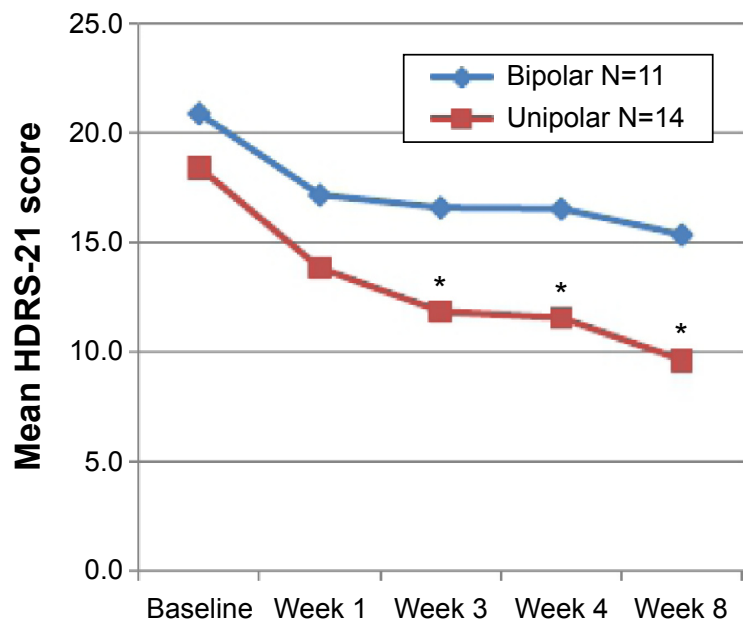

Figure 3 HDRS-2I scores of unipolar and bipolar patients throughout the study. Notes: As of week 2, unipolar patients have a significantly better response. $* P<0.01$ (between unipolar and bipolar patients).

Abbreviation: HDRS-2I, Hamilton Depression Rating Scale (2I items). 
type of depression and season of treatment, but no significant differences in uni-/bipolarity were found in the distribution of patients over spring-summer and autumn-winter $\left(\chi^{2}=1.924\right.$; $P=0.165$ ) (Figure 4).

Finally, we analyzed the changes in psychopathological features during BLT augmentation. No significant changes in anhedonic features were observed at the end of the study in the overall sample (Wilcoxon signed-ranks test: $Z=-0.514$; $P=0.607)$. Conversely, comparison of DRRS scores at baseline and at the end of the study (14.5 \pm 9.3 and $8.1 \pm 6.8$, respectively) showed a statistically significant improvement of psychomotor retardation (Wilcoxon signed-ranks test: $Z=-3.327 ; P=0.001)$. No statistically significant differences in SHAPS or DRRS scores were found in comparing unipolar and bipolar patients (Table 2).

\section{Discussion}

Previous trials on the efficacy of chronotherapeutic interventions in treatment-resistant depressed patients mainly focused on the combined chronotherapeutic intervention ${ }^{25,26}$ or were mostly conducted during hospitalization. ${ }^{27}$ To the best of our knowledge, this is the first study addressing the BLT augmentation of psychopharmacotherapy, not combined to other chronotherapeutics, in the management of DTD

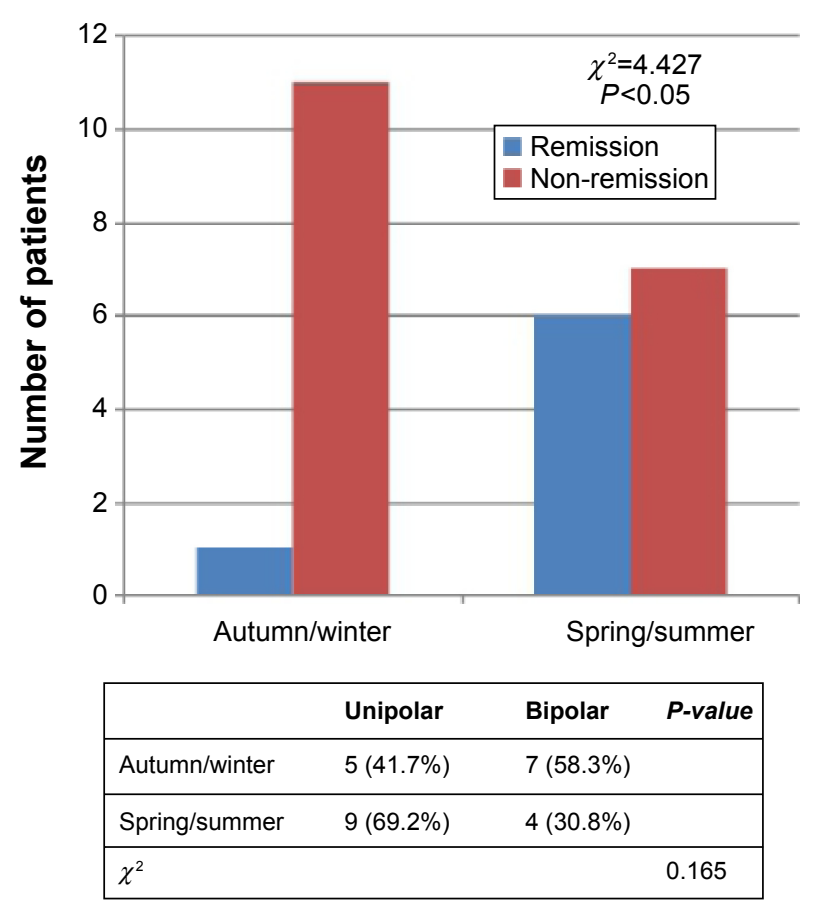

Figure 4 Patients receiving BLT augmentation in the spring/summer season had a significantly higher remission rate.

Note: No significant differences were found in the distribution of patients within spring-summer and autumn-winter (crosstab).

Abbreviation: BLT, bright light therapy. outpatients, including both bipolar and unipolar subjects. In our experience, this therapeutic approach appeared not only helpful but also simple and safe for such a vulnerable, still not well-studied, clinical population.

Our study also seems to confirm an improvement of depressive core symptoms during BLT, as measured by HDRS-6 subscale, supporting the hypothesis of its genuine antidepressant effect. ${ }^{7}$ Significant changes in depressive symptoms were observed since the first week of therapy in keeping with previous findings on seasonal and nonseasonal depression. ${ }^{6,7,11}$ This improvement endured throughout the continuation phase, and all patients who responded to BLT augmentation still maintained the favorable outcome after 5 weeks from BLT discontinuation; therefore, we supposed that BLT augmentation in our patients could boost the antidepressant effect of ongoing treatment. According to previous observations in TRD, more than one-third of our sample (36\%) still showed a clinical response at the end of the study. ${ }^{25,26}$

Although both unipolar and bipolar patients showed a substantial clinical improvement, the outcome and the maintenance of therapeutic benefits were significantly better in the unipolar group. Up to date, only few trials on BLT, not in combination with other chronotherapeutics, have specifically looked at patients with bipolar depression, ${ }^{9,10}$ and their findings suggested that BLT might also be helpful in nonseasonal bipolar depression. ${ }^{28}$ These results did not clearly emerge in our study, since unipolar patients showed a greater improvement (as from week 3 ) and a significantly better response rate after week 8 (eight unipolar vs one bipolar). More in general, BLT appeared to be useful and safe for both unipolar and bipolar subjects, since none of our patients experienced side effects or (hypo)manic switches or significant changes in MRS scores.

Considering the effect of season of treatment on the course of illness, patients treated during spring-summer period appeared to have a significantly better remission rate (HDRS-21 score <8) at the end of follow-up (Figure 4). Previous studies focusing on the role of the season in BLT augmentation reported that during autumn and winter, BLT timing early in the morning was associated with a better response in unipolar depressed patients, while during spring and summer, the clinical response was unrelated to BLT timing during the day. ${ }^{18}$ According to our results, we hypothesized that the differences reported might have been influenced by seasonal changes of the photoperiod, with an increased daylight exposure during spring and summer extending the therapeutic benefit of BLT. 
Although our findings are in line with the previous observations in nonseasonal major depressed patients, ${ }^{29-31}$ they must be interpreted with caution because of the limitations of our study. First, the open-label design and the lack of a placebo or active control group might bias our results. Therefore, we cannot exclude that high response rates observed in our sample were partially driven by the placebo response, even if more severe depressed patients are less likely to show a placebo effect. ${ }^{32-35} \mathrm{We}$ tried to reduce observer bias and eventual halo effects by keeping the patient rater blind to diagnosis and treatment. ${ }^{36}$ Another major limitation is the relatively small number of subjects recruited. Finally, our results might also have been influenced in an unpredictable way by the psychometric evaluation that has not yet been specifically validated for TRD. ${ }^{37}$

According to different psychopathological dimension analyses, anhedonic symptoms persisted after BLT augmentation, regardless of clinical remission. This observation is in keeping with previous findings on anhedonic symptoms that are particularly difficult to treat ${ }^{38}$ and might predict a poor treatment outcome ${ }^{39}$ due to some possible dysfunctions in the neurobiological mechanisms of hedonic response and reward processing that may persist, irrespective of mood state ${ }^{40}$ and clinical changes. ${ }^{41}$

On the contrary, in our sample, BLT augmentation led to a significant improvement of psychomotor retardation as reported by DRRS score changes. This is in agreement with Martiny et al who found that the retardation score (item 8 of HDRS) was the most sensitive item in discriminating the effect of BLT compared to the placebo treatment group. ${ }^{7}$ Accordingly, recent literature on Parkinson's disease also shows a positive effect of BLT not only on mood but also on motor function. ${ }^{42-44}$ Basal ganglia through a dysfunctional dopaminergic neurotransmission probably play a crucial role in pathophysiology of psychomotor changes of mood disorders. ${ }^{45-48}$ Striatal dopamine metabolism seems to be regulated by CLOCK proteins, and stimulation of dopamine receptors affects the rhythm of expression of $C L O C K$ genes in the striatum. ${ }^{43,49-51}$ Dopamine also regulates the rhythmic expression of melanopsin in retinal ganglion cells, thereby influencing the entrainment of the circadian rhythm by light..$^{52}$ Although the mechanism of action is still unknown, our evidence might suggest a specific dopamine-increasing activity of BLT.

\section{Conclusion}

In conclusion, in our experience, BLT augmentation appeared to be a simple, safe, well-tolerated, and low-cost strategy in outpatient settings, for both unipolar and bipolar patients. BLT augmentation was particularly helpful for unipolar DTD patients adding the assumption that during autumn and winter, it might be necessary to increase the intensity of BLT (ie, longer exposure or more lux) in order to achieve satisfying results. This augmentation strategy might also have a clinically significant influence on depressive "core" symptoms and on psychomotor retardation, a key feature of depression suggesting a specific dopamine-increasing activity of BLT.

These preliminary findings deserve further investigation in this complex clinical population who requires tailored combined treatment approaches. When considering the major limitations of our study, these results need to be confirmed in placebo-controlled, randomized, double-blind clinical trial on a larger sample.

\section{Disclosure}

The authors report no conflicts of interest in this work.

\section{References}

1. Murray CJ, Lopez AD. Alternative projections of mortality and disability by cause 1990-2020: global burden of disease study. Lancet. 1997;349: 1498-1504.

2. Berlim MT, Fleck MP, Turecki G. Current trends in the assessment and somatic treatment of resistant/refractory major depression: an overview. Ann Med. 2008;40:149-159.

3. Gaynes BN. Identifying difficult-to-treat depression: differential diagnosis, subtypes, and comorbidities. J Clin Psychiatry. 2009;70(suppl 6): $10-15$.

4. Maina G, Portaleone F, Picco C, Bogetto F. Definition and therapeutic strategies of treatment resistant depression: a review. Riv Psichiatr. 2003;38: $225-240$.

5. Rush AJ, Thase ME, Dube S. Research issues in the study of difficultto-treat depression. Biol Psychiatry. 2003;53:743-753.

6. Benedetti F, Colombo C, Pontiggia A, Bernasconi A, Florita M, Smeraldi E. Morning light treatment hastens the antidepressant effect of citalopram: a placebo-controlled trial. J Clin Psychiatry. 2003;64:648-653.

7. Martiny K, Lunde M, Unden M, Dam H, Bech P. Adjunctive bright light in non-seasonal major depression: results from clinician-rated depression scales. Acta Psychiatr Scand. 2005;112:117-125.

8. Benedetti F. Antidepressant chronotherapeutics for bipolar depression. Dialogues Clin Neurosci. 2012;14:401-411.

9. Leibenluft E, Turner EH, Feldman-Naim S, Schwartz PJ, Wehr TA, Rosenthal NE. Light therapy in patients with rapid cycling bipolar disorder: preliminary results. Psychopharmacol Bull. 1995;31:705-710.

10. Sit D, Wisner KL, Hanusa BH, Stull S, Terman M. Light therapy for bipolar disorder: a case series in women. Bipolar Disord. 2007;9: 918-927.

11. Martiny K, Lunde M, Simonsen C, et al. Relapse prevention by citalopram in sad patients responding to 1 week of light therapy. A placebocontrolled study. Acta Psychiatr Scand. 2004;109:230-234.

12. Terman M, Terman JS. Bright light therapy: side effects and benefits across the symptom spectrum. J Clin Psychiatry. 1999;60:799-808. [quiz 809].

13. Hamilton M. A rating scale for depression. J Neurol Neurosurg Psychiatry. 1960;23:56-62.

14. Young RC, Biggs JT, Ziegler VE, Meyer DA. A rating scale for mania: reliability, validity and sensitivity. Br J Psychiatry. 1978;133: 429-435.

15. O’Sullivan RL, Fava M, Agustin C, Baer L, Rosenbaum JF. Sensitivity of the six-item hamilton depression rating scale. Acta Psychiatr Scand. 1997; 95:379-384. 
16. Snaith RP, Hamilton M, Morley S, Humayan A, Hargreaves D, Trigwell P. A scale for the assessment of hedonic tone the SnaithHamilton pleasure scale. Br J Psychiatry. 1995;167:99-103.

17. Widlocher DJ. Psychomotor retardation: clinical, theoretical, and psychometric aspects. Psychiatr Clin North Am. 1983;6:27-40.

18. Dallaspezia S, Benedetti F, Colombo C, et al. Optimized light therapy for non-seasonal major depressive disorder: effects of timing and season. J Affect Disord. 2012;138:337-342.

19. Goel N, Terman M, Terman JS, Macchi MM, Stewart JW. Controlled trial of bright light and negative air ions for chronic depression. Psychol Med. 2005;35:945-955.

20. Horne JA, Ostberg O. A self-assessment questionnaire to determine morningness-eveningness in human circadian rhythms. Int J Chronobiol. 1976;4:97-110.

21. Terman JS, Terman M, Lo ES, Cooper TB. Circadian time of morning light administration and therapeutic response in winter depression. Arch Gen Psychiatry. 2001;58:69-75.

22. Wirz-Justice A, Benedetti F, Terman M. Chronotherapeutics for Affective Disorders: A Clinician's Manual for Light and Wake Therapy. Basel: Karger; 2009.

23. Golden RN, Gaynes BN, Ekstrom RD, et al. The efficacy of light therapy in the treatment of mood disorders: a review and meta-analysis of the evidence. Am J Psychiatry. 2005; 162:656-662.

24. Terman M, Terman JS, Quitkin FM, McGrath PJ, Stewart JW, Rafferty B. Light therapy for seasonal affective disorder. A review of efficacy. Neuropsychopharmacology. 1989;2:1-22.

25. Benedetti F, Barbini B, Fulgosi MC, et al. Combined total sleep deprivation and light therapy in the treatment of drug-resistant bipolar depression: acute response and long-term remission rates. J Clin Psychiatry. 2005;66: $1535-1540$

26. Echizenya M, Suda H, Takeshima M, Inomata Y, Shimizu T. Total sleep deprivation followed by sleep phase advance and bright light therapy in drug-resistant mood disorders. J Affect Disord. 2013;144: 28-33.

27. Prasko J, Brunovsky M, Latalova K, et al. Augmentation of antidepressants with bright light therapy in patients with comorbid depression and borderline personality disorder. Biomed Pap Med Fac Univ Palacky Olomouc Czech Repub. 2010;154:355-361.

28. Deltito JA, Moline M, Pollak C, Martin LY, Maremmani I. Effects of phototherapy on non-seasonal unipolar and bipolar depressive spectrum disorders. J Affect Disord. 1991;23:231-237.

29. Beauchemin KM, Hays P. Phototherapy is a useful adjunct in the treatment of depressed in-patients. Acta Psychiatr Scand. 1997;95: 424-427.

30. Levitt AJ, Joffe RT, Kennedy SH. Bright light augmentation in antidepressant nonresponders. J Clin Psychiatry. 1991;52:336-337.

31. Martiny K. Adjunctive bright light in non-seasonal major depression. Acta Psychiatr Scand. 2004;110(Suppl 425):7-28.

32. De Berardis D, Marini S, Serroni N, et al. S-adenosyl-1-methionine augmentation in patients with stage II treatment-resistant major depressive disorder: an open label, fixed dose, single-blind study. ScientificWorldJournal. 2013;2013:204649.

33. Elkin I, Gibbons RD, Shea MT, et al. Initial severity and differential treatment outcome in the national institute of mental health treatment of depression collaborative research program. J Consult Clin Psychol. 1995;63:841-847.
34. Walsh BT, Seidman SN, Sysko R, Gould M. Placebo response in studies of major depression: variable, substantial, and growing. JAMA. 2002;287: $1840-1847$.

35. Wilcox CS, Cohn JB, Linden RD, et al. Predictors of placebo response: a retrospective analysis. Psychopharmacol Bull. 1992;28:157-162.

36. Sarchiapone M, Amore M, De Risio S, et al. Mirtazapine in the treatment of panic disorder: an open-label trial. Int Clin Psychopharmacol. 2003;18: 35-38.

37. Bech P, Lauritzen L, Lunde M, et al. Psychometric analysis of the melancholia scale in trials with non-pharmacological augmentation of patients with therapy-resistant depression. Acta Neuropsychiatr. 2014;26:155-160.

38. Dunlop BW, Nemeroff CB. The role of dopamine in the pathophysiology of depression. Arch Gen Psychiatry. 2007;64:327-337.

39. Spijker J, Bijl RV, de Graaf R, Nolen WA. Determinants of poor 1-year outcome of DSM-III-R major depression in the general population: results of the Netherlands mental health survey and incidence study (NEMESIS). Acta Psychiatr Scand. 2001;103:122-130.

40. Di Nicola M, De Risio L, Battaglia C, et al. Reduced hedonic capacity in euthymic bipolar subjects: a trait-like feature? J Affect Disord. 2013;147: 446-450.

41. Camardese G, Di Giuda D, Carli V, et al. Changing of dopamine transporter binding in depressed patients with anhedonia during treatment. Eur Neuropsychopharm. 2006;16:S267-S267.

42. Paus S, Schmitz-Hubsch T, Wullner U, Vogel A, Klockgether T, Abele M. Bright light therapy in Parkinson's disease: a pilot study. Mov Disord. 2007;22:1495-1498.

43. Rutten S, Vriend C, van den Heuvel OA, Smit JH, Berendse HW, van der Werf YD. Bright light therapy in Parkinson's disease: an overview of the background and evidence. Parkinson's Dis. 2012;2012:767105.

44. Willis GL, Turner EJ. Primary and secondary features of parkinson's disease improve with strategic exposure to bright light: a case series study. Chronobiol Int. 2007;24:521-537.

45. Buyukdura JS, McClintock SM, Croarkin PE. Psychomotor retardation in depression: biological underpinnings, measurement, and treatment. Prog Neuropsychopharmacol Biol Psychiatry. 2011;35:395-409.

46. Camardese G, Di Giuda D, Mosca L, Giordano A, Bria P. DAT binding and psychopathological features in depressed patients. Eur Psychiatry. 2007;22:S26-S26.

47. Herrero MT, Barcia C, Navarro JM. Functional anatomy of thalamus and basal ganglia. Childs Nerv Syst. 2002;18:386-404.

48. Meyer JH, McNeely HE, Sagrati S, et al. Elevated putamen D(2) receptor binding potential in major depression with motor retardation: an [11C]raclopride positron emission tomography study. Am J Psychiatry. 2006;163:1594-1602.

49. Hampp G, Ripperger JA, Houben T, et al. Regulation of monoamine oxidase a by circadian-clock components implies clock influence on mood. Curr Biol. 2008;18:678-683.

50. Imbesi M, Yildiz S, Dirim Arslan A, Sharma R, Manev H, Uz T. Dopamine receptor-mediated regulation of neuronal "clock"gene expression. Neuroscience. 2009;158:537-544.

51. McClung CA. Circadian genes, rhythms and the biology of mood disorders. Pharmacol Ther. 2007;114:222-232.

52. Sakamoto K, Liu C, Kasamatsu M, Pozdeyev NV, Iuvone PM, Tosini G. Dopamine regulates melanopsin mRNA expression in intrinsically photosensitive retinal ganglion cells. Eur J Neurosci. 2005;22: 3129-3136.
Neuropsychiatric Disease and Treatment

\section{Publish your work in this journal}

Neuropsychiatric Disease and Treatment is an international, peerreviewed journal of clinical therapeutics and pharmacology focusing on concise rapid reporting of clinical or pre-clinical studies on a range of neuropsychiatric and neurological disorders. This journal is indexed on PubMed Central, the 'PsycINFO' database and CAS,

\section{Dovepress}

and is the official journal of The International Neuropsychiatric Association (INA). The manuscript management system is completely online and includes a very quick and fair peer-review system, which is all easy to use. Visit http://www.dovepress.com/testimonials.php to read real quotes from published authors. 